\title{
A leitura da Lenda da Dama do Pé de Cabra na perspectiva das novas mídias digitais
}

Amanda Ingrid dos Santos ${ }^{1}$ Jonabelle de Andrade, Mateus Alves Nedbajluk ${ }^{3}$, Carlos Eduardo Zlatic ${ }^{4}$

Resumo: A narrativa medieval conhecida como A lenda da Dama do Pé de Cabra, primeiramente registrada no Livro de Linhagens do Conde D. Pedro, foi assim chamada e difundida por Alexandre Herculano e, mais recentemente, pelo Sítio do Pica-Pau Amarelo, programa transmitido pela Rede Globo. A modificação de elementos em relação ao registro original e a ausência de qualquer intenção de análise historiográfica sustentada pelo autor português e pela rede de TV incitaram o desenvolvimento de um produto audiovisual que abarcasse essa perspectiva. Diante disso, o presente artigo pretende abordar o autor e o contexto de produção da lenda e os potenciais oferecidos pelo uso das novas mídias digitais para a produção e disponibilização de conhecimento na contemporaneidade a fim de debater as potencialidades do desenvolvimento de produtos audiovisuais voltados para um público cada vez mais atraído por meios não escritos de transmissão de conhecimento.

Palavras-chave: Lenda da Dama do Pé de Cabra, D. Pedro Afonso, novas mídias digitais.

Abstract: The medieval narrative known as Legend of the Lady with the Cloven Hoof, first registered in the Book of Lineages of the Count D. Pedro, was thus called and publicized by Alexandre Herculano and, more recently, by the Sítio do Picapau Amarelo, a show broadcast by Rede Globo. The modification of elements in relation to the original registry and the absence of any intention of historiographical analysis sustained by the Portuguese author

1 Graduanda em História pela Universidade Federal do Paraná. Contato: ingridamanda1999@gmail.com

2 Graduanda em História pela Universidade Federal do Paraná. Contato: andrade_historia@hotmail.com

3 Graduando em História pela Universidade Federal do Paraná. Contato: mateusnedbajluk@gmail.com

${ }^{4}$ Pós-doutorando PNPD/CAPES junto ao Programa de Pós-Graduação em História da Universidade Federal do Paraná. Contato: carloszlatic@gmail.com. O presente trabalho foi realizado com apoio da Coordenação de Aperfeiçoamento de Pessoal de Nível Superior - Brasil (CAPES) - Código de Financiamento 001.

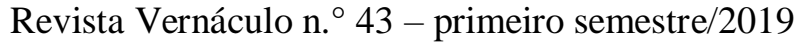

ISSN $2317-4021$ 
and the TV network stimulated the development of an audiovisual product that embraced this perspective. The present paper intends to approach the author and context of the production of the legend and the potential offered by the use of the new digital media for the production and diffusion of knowledge in the contemporaneity in order to discuss the potential of the development of audiovisual products aimed at an audience increasingly interested by nonwritten means of transmitting knowledge.

Keywords: Legend of the Lady with the Cloven Hoof, D. Pedro Afonso, new digital media.

Dentre a variedade de narrativas medievais registradas pelo conde D. Pedro de Barcelos em seu Livro de Linhagens, uma delas chama atenção pelo eco que encontra na contemporaneidade. Trata-se da lenda que conta a trajetória de D. Diego Lopes que, depois de se encantar por uma formosa figura feminina, descobre que ela era uma criatura mágica e detentora de uma característica peculiar: tinha os pés de uma cabra ${ }^{5}$.

A Lenda da Dama do Pé de Cabra, assim chamada pela primeira vez por Alexandre Herculano em seu livro Lendas e Narrativas, encontrou difusão no meio escrito depois que o autor a resgatou da tradição medieval e ampliou sua forma e conteúdo a partir de influências do Romantismo. Na obra, escrita em meados do século XIX, a narrativa, apresentada em tons de uma veracidade a ela atribuída por seu registro em um velho livro, é fortemente marcada pela perspectiva cristã, tanto para construir uma ideia de moral, quanto para a afirmação

${ }^{5}$ Livro de Linhagens do Conde D. Pedro. Edição crítica por José Mattoso. In: Portvgaliae Monvmenta Historica. Nova Série - vol. II. Lisboa: Academia das Ciência, 1980. p. 138-140.

Revista Vernáculo n. ${ }^{\circ} 43$ - primeiro semestre/2019

ISSN 2317-4021 
nacionalista em relação ao outro, o muçulmano. $\mathrm{O}$ primeiro aspecto se evidencia pela imagem diabólica associada à Dama, incapaz de reconhecer bem ou mal; o segundo, pela atribuição de adjetivos pejorativos aos muçulmanos, assemelhando-os aos cães ${ }^{6}$.

Mais recentemente, a lenda da Dama do Pé de Cabra foi apresentada ao amplo público quando, em 2004, tematizou de uma série de capítulos do Sítio do Picapau Amarelo, atração desenvolvida pela Rede Globo a partir da obra de Monteiro Lobato. Embora o programa referencie a obra de Alexandre Herculano, o faz apenas ao utilizar o nome do personagem Argimiro, enamorado da Dama do Pé de Cabra, que nessa produção passou a se chamar Isabel, nome até então inexistente nas versões anteriores da lenda ${ }^{7}$.

Consideradas essas variações de uma mesma história e, no caso de Alexandre Herculano e do Sítio do Picapau Amarelo, sua associação ao caráter de entretenimento do livro e da comunicação em massa, portanto, diferente das intenções originais daquela registrada por D. Pedro de Barcelos em seu Livro de Linhagens, esse artigo pretende analisar a viabilidade e a abordagem no desenvolvimento de um produto audiovisual que seja capaz de apresentar tanto a lenda da Dama do Pé de Cabra em sua concepção medieval, quanto de compreender essa narrativa pela perspectiva historiográfica de seu momento de

6 Herculano, Alexandre. A Dama do pé-de-cabra. Domínio Público: Wikisource, 2007.

${ }^{7}$ Os vídeos da série televisiva O Sítio do Picapau Amarelo utilizados como fonte para esse artigo encontram-se disponíveis de maneira dispersa no YouTube.

Revista Vernáculo n. ${ }^{\circ} 43$ - primeiro semestre/2019

ISSN 2317-4021 
produção: o autor, seu contexto histórico, suas intenções e as do grupo social ao qual pertence aquela tradição.

Antes de avançar, cumpre informar que a intenção de produzir um conteúdo audiovisual que abordasse a narrativa contida no Livro de Linhagens pela perspectiva da História motivou e orientou o curso extensão Um celular na mão e uma lenda medieval na cabeça! e a videoaula, gerada ao final das atividades, se encontra disponível ao público por meio do YouTube, com o título A Lenda da Dama do Pé de Cabra: uma análise historiográfica ${ }^{8}$.

Tendo em vista os objetivos anunciados, o presente artigo será dividido em dois pontos. $\mathrm{O}$ primeiro deles será dedicado à compreensão do caráter historiográfico da lenda da Dama do Pé de Cabra, ou seja, o autor e suas intenções, o contexto histórico e as pretensões políticas almejadas pela narrativa. Em seguida, serão analisados os elementos técnicos e as inovações experimentadas no campo da internet e tecnologias móveis, assim possibilitando uma reflexão a respeito das formas de circulação de conhecimento e modificações de comportamentos sociais no século XXI. Dessa forma, busca-se analisar como a emergência das novas formas de produção e veiculação de informação na contemporaneidade pode contribuir para a difusão de um conhecimento em grande medida registrado por meio da escrita, ampliando o acesso desses saberes a um grupo maior de pessoas.

8 Disponível em: https://www.youtube.com/watch?v=LzrrtP4Egvg\&t=14s. Acesso em: 07/01/2019.

Revista Vernáculo n. ${ }^{\circ} 43$ - primeiro semestre/2019

ISSN 2317-4021 


\section{A lenda da Dama e a crítica historiográfica}

O Livro de Linhagens do Conde D. Pedro insere-se num contexto de enriquecimento literário das cortes portuguesas e de disputas entre o poder régio e o nobiliárquico. Filho ilegítimo de D. Dinis, D. Pedro cresceu em um ambiente culturalmente rico, marcado pela produção trovadoresca - a exemplo de seu pai, autor de uma variedade de canções -, mas também social e politicamente instável, como havia sido o reinado dionisino desde o seu princípio, quando o rei entrou em guerra contra seu próprio irmão, o infante D. Afonso ${ }^{9}$.

Outra disputa que influenciou fortemente a trajetória de D. Pedro foi a guerra civil que marcou o reino de Portugal em finais do governo de D. Dinis, quando esse rei entrou em confronto com seu primogênito, o futuro Afonso IV, irmão do conde de Barcelos. Conforme o suserano português desenvolveu suas práticas centralizadoras, criou um constante senso de resistência entre os nobres, primeiramente passiva, ao cercear as "imunidades senhoriais". Esgotadas a possibilidades de oposição, os membros da nobreza insatisfeitos com a política dionisina se associaram ao herdeiro do trono para iniciar uma revolta. Foi nesse contexto que, buscando aproximar o filho bastardo, D. Dinis doou o condado de Barcelos a Pedro Afonso no ano de $1314^{10}$.

\footnotetext{
${ }^{9}$ MOCELIM, Adriana. "Segundo conta a estoria..." A Crônica Geral de Espanha de 1344 como um retrato modelar da sociedade hispânica tardo medieval. Tese (Doutorado em História), UFPR, Curitiba, 2013, p. 258-261.

${ }^{10}$ Ibid., p. 268.
}

Revista Vernáculo n. ${ }^{\circ} 43$ - primeiro semestre/2019

ISSN 2317-4021 
Com o agravar das tensões que levaram Portugal a uma guerra civil entre 1319 e 1324, Pedro Afonso deixou o reino em direção a Castela, onde "pode entrar em contato com a atividade literária lá praticada desde os tempos de seu bisavô Afonso X, que ganharia novo vigor no Reinado de Afonso XI, e ainda com D. João Manuel, segundo Lindley Cintra, o maior prosador da Idade Média Castelhana" ${ }^{11}$.

Depois de retornar ao reino de Portugal em 1322, a pedido de seu irmão, o infante Afonso, D. Pedro desenvolveu atividades a fim de estabelecer a concórdia entre D. Dinis e o herdeiro do trono, demonstrando grandes habilidades conciliatórias e forte influência sobre ambos. A esse respeito, Adriama Mocelim recorre à Crónica Geral de Espanha de 1344, também escrita pelo conde Barcelos, para frisar aquela postura conciliadora e afirma:

Ao justificar-se o Conde coloca que sempre esteve ao lado do pai, não deixou de servi-lo. Fora, segundo ele o pai que assim o quis, colocando-o fora de suas terras sem motivo, ou merecimento. Isenta-se assim de culpa nos eventos que levaram ao seu desterro, novamente apontando para o perigo dos maus conselheiros e do que pode acontecer ao dar-lhes ouvido. Ao regressar de Castela não teria participado de nenhum combate contra o Rei. Ressalta seu papel conciliador ao 'sugerir' ao Rei que alcançasse a concórdia com o Infante, finalizando assim os conflitos que estavam gerando instabilidade no Reino, fragilizando-o ${ }^{12}$.

Nesta mesma crônica, o conde tece elogios ao rei Afonso IV, agora ocupante do trono, enaltecendo-o "pela prática da justiça,

${ }_{12}^{11}$ Ibid., p. 273.

Revista Vernáculo n. ${ }^{\circ} 43$ - primeiro semestre/2019

ISSN 2317-4021 
elemento que fora de grande relevância na caracterização do Rei Dinis, não sendo ela questionada ao longo do relato"13. Durante o resto de sua vida, teve sua posição na corte cada vez mais reduzida e acabou por se recolher seu trabalho solitário que resultou na Crónica de 1344 e no Livro de Linhagens.

Pedro Afonso demonstrou grande habilidade no manejo do jogo político interno ao reino português. As mudanças levadas a cabo por D. Dinis mostram-se efetivas, haja vista que se mantiveram ao longo do próximo reinado, como aponta Matoso: "o processo de organização do Estado se revela, no reinado seguinte, como irreversível. Os poderes senhoriais, aparentemente triunfantes, não deixarão mais de perder terreno perante o fortalecimento do Estado monárquico" ${ }^{14}$.

A postura conciliatória do conde foi reforçada por sua atuação a favor da união dos reis de Portugal e de Castela com o objetivo de frear o avanço dos muçulmanos vindos de Marrocos, o que se deu de maneira vitoriosa na Batalha do Salado, travada em 1340. Este evento é caracterizado por Luís Krus como "acontecimento terminal da narrativa do passado hispânico que se propôs, dando-lhe, tal como a conquista de Sevilha para a Primeira Crônica Geral de Espanha de Afonso X, a categoria de marco simbólico na história peninsular de seu tempo"15.

${ }^{13}$ Ibid., p. 281.

${ }^{14}$ MATTOSO, José. Identificação de um país: ensaio sobre as origens de Portugal (1096-1325). Apud Ibid., p. 279.

${ }^{15}$ KRUS, Luís. A concepção nobiliárquica do espaço ibérico. Geografia dos livros de linhagens medievais portugueses (1280-1380). Apud Ibid., p. 283.

Revista Vernáculo n. ${ }^{\circ} 43$ - primeiro semestre/2019

ISSN 2317-4021 
A habilidade da concórdia possuída pelo conde D. Pedro também favorecia as políticas desenroladas ao longo dos reinados de Afonso III, D. Dinis e Afonso IV, monarcas que colocaram em curso um projeto centralizador da autoridade régia e, em decorrência disso, demandavam uma harmonia em torno do poder régio, que cada vez mais recorria ao uso da justiça contra possíveis usurpadores ou nobres revoltosos. Conforme aponta Mattoso, na Idade Média

Existem pelo menos dois princípios de legitimação [do exercício da força]: o sancionamento religioso conferido pelo poder espiritual, e a pertença ao grupo social que pode exercer a autoridade, e a transmite por meio do nascimento. Ambos se baseiam em representações teóricas orientadoras da prática: uma invoca a origem divina do poder [...]; outra apela para o consenso social que atribui funções próprias aos componentes de três grandes ordens em que a humanidade se divide: os oratores, belatores e laboratores; a divisão e a complementaridade das tarefas, e a reprodução perpétua de cada uma das três ordens asseguram a estabilidade social. São duas formas diferentes de legitimação do poder. Ambos recusam a arbitrariedade da força ${ }^{16}$.

Ainda segundo José Mattoso, existia outro princípio de legitimidade na Idade Média: o dos poderes extraordinários transmitidos por meio do sangue. Essa ideia, presente sobretudo na tradição germânica, estava voltada para a legitimação da condição social superior atribuída aos nobres, independente da riqueza possuída por eles. Igualmente pautado na divisão tripartite da sociedade, esse

${ }^{16}$ MATTOSO, José. Legitimação e linhagem. In: DACOSTA, Arsenio (Ed.). La conciencia de los antepasados. Madrid: Marcial Pons, 2014. p. 18.

Revista Vernáculo n. ${ }^{\circ} 43$ - primeiro semestre/2019

ISSN 2317-4021 
ideário carrega uma ambiguidade ao não determinar se a autoridade pública era inerente à função sacra ou guerreira, apontando para um acordo entre os oratores e os belatores em que era necessária tanto a força para os sacerdotes, quanto os ditames de condições de legitimidade advindo da religião aos guerreiros ${ }^{17}$.

Tal legitimidade do poder régio era transmitida pelo sangue, e o interesse do conde D. Pedro em se dedicar a linhagística buscava não só a legitimação da autoridade pública, mas também a demarcação do prestígio naquela sociedade, pautado justamente no exercício de funções sócio-políticas. Dessa forma, José Mattoso assinala: "As genealogias pretendem registrar a superioridade hierárquica daquele conjunto de indivíduos que a reivindica em virtude do seu próprio nascimento numa família determinada" ${ }^{18}$.

Outra característica da narrativa, seu caráter mítico, pode ser constatada de maneira sistemática não apenas na literatura da Península Ibérica, mas na de todo o Ocidente Medieval, como aponta Jaume Aurell. O gênero literário da genealogia tem um formato a-histórico e atemporal, voltado para as origens lendárias dos antepassados que fundavam as linhagens nobres e funcionava como uma importante ferramenta de legitimação dos poderes da nobreza, mais eficiente que a expansão militar e as estratégias matrimoniais. Ainda segundo aquele autor:

${ }^{17}$ MATTOSO, José. Legitimação e linhagem. In: DACOSTA, Arsenio (Ed.). La conciencia de los antepasados. Madrid: Marcial Pons, 2014. p. 18-19.

${ }^{18}$ Ibid., p. 22.

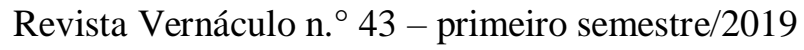

ISSN $2317-4021$ 
Las genealogías de los condes suplen entonces con eficacia a los sobrios anales altomedievales. La genealogía es asumida por los cronistas medievales como un medio privilegiado para establecer una sucesión ordenada y rigurosa de los hechos, que son los verdaderos fundantes de la estructura de la historia. Prolifera así una literatura propiamente histórico-historiográfica, que aprende a convivir con las leyendas épicas, percibidas como ficcionales por sus lectores. ${ }^{19}$

Assim, a escrita do conde D. Pedro estava intrinsicamente ligada à sua condição social. Enquanto nobre, remontava suas origens linhagísticas a um tronco de dinastias régias peninsulares dos reinos visigodos, atribuindo à aristocracia portuguesa a qualidade que Luís Krus trata por "aristocracia guerreira peninsular, procurando demonstrar como suas origens hispânicas nela predestinavam a milícia de Cristo a quem estaria reservada a proteção e a salvação de toda a Cristandade" 20 . A posição social que se justifica nas obras do conde D. Pedro é, portanto, a do combate ao inimigo religioso, mas também a de quem busca justificar a centralização por parte da autoridade régia, exercido por seu pai e depois por seu irmão, assim almejando contribuir para o estabelecimento de uma harmonia construtiva para a ordem régia portuguesa.

As obras deixadas pelo Conde representam, dentro do contexto peninsular, uma forma de retomar o ideal

${ }^{19}$ AURELL, Jaume. Memoria dinástica y mitos fundadores: la construcción social del pasado en la Edad Media, in: La conciencia de los antepasados, Madrid: Marcial Pons, 2014, p. 305.

${ }^{20}$ KRUS, Luís. O discurso sobre o passado na legitimação do senhoralismo português dos finais do século XIII, in: A Construção do Passado Medieval: textos inéditos e publicados, Lisboa: IEM - Instituto de Estudos Medievais, 2011, p. 178.

Revista Vernáculo n. ${ }^{\circ} 43$ - primeiro semestre/2019

ISSN 2317-4021 
cruzadístico, revelando à fidalguia e à realeza peninsulares a consciência de seu papel na sociedade. Tal consciência era transmitida pelo Conde através de suas obras, em muito influenciadas pela sua atuação junto à corte do Rei Dinis, pelas viagens que pode fazer ao lado do Rei, ou como inquisidor régio e ainda graças ao período em que esteve exilado em Castela e dos contatos lá estabelecidos. ${ }^{21}$

Dessa forma, as narrativas registradas no Livro de Linhagens cumprem este papel legitimatório de grupos específicos na constelação política do contexto português e leonês-castelhano, tendo um sentido conciliatório a partir da busca de harmonia entre nobreza e realeza. Para que se possa compreender como essas intenções estavam presentes na lenda da Dama do Pé de Cabra, urge apresentar seu conteúdo de modo mais detalhado para, depois disso, analisar seu conteúdo em uma perspectiva historiográfica.

Como registrado no Livro de Linhagens ${ }^{22}$, D. Diego Lopes estava em meio a uma caçada quando ouviu a voz de uma mulher. Ao se aproximar, constatou que era muito bonita e bem vestida - apesar da característica marcante de seus pés serem cindidos ao meio como os de uma cabra -, atributos que fizeram com que ele se apaixonasse por ela, ao que se seguiu um pedido de casamento. Ela prontamente aceitou o pedido, mas impôs uma condição ao nobre: prometer que jamais iria se santificar. A concordância com essa demanda abriu espaço para o

${ }^{21}$ MOCELIM, Adriana. "Segundo conta a estoria...” A Crônica Geral de Espanha de 1344 como um retrato modelar da sociedade hispânica tardo medieval. Tese (Doutorado em História), UFPR, Curitiba, 2013. p. 291.

${ }^{22}$ Livro de Linhagens do Conde D. Pedro. Edição crítica por José Mattoso. In: Portvgaliae Monvmenta Historica. Nova Série - vol. II. Lisboa: Academia das Ciência, 1980. p. 138-140.

Revista Vernáculo n. ${ }^{\circ} 43$ - primeiro semestre/2019

ISSN 2317-4021 
enlace e, em seguida, o casal teve um filho, chamado de Iñigo Guerra, e uma filha, cujo nome não é informado pela fonte.

Seguindo a narrativa, o conde D. Pedro registra que, em determinado dia, enquanto o casal e os filhos estavam sentados à mesa comendo um porco, D. Diego Lopes atirou um osso a dois cães. Enquanto brigavam pelo prêmio, o menor dos cachorros se lançou sobre o maior e o matou. Impressionado pela cena, o nobre exclamou: "Santa Maria val, quem vio nunca tal cousa!”. Diante da santificação do esposo, a dama deixou a residência em direção à floresta levando consigo sua filha, ao passo que o pai impediu a saída do filho.

Depois de um tempo, D. Diego Lopes foi guerrear contra os muçulmanos e acabou por cair cativo em Toledo. Sabendo do ocorrido, Iñigo Guerra buscava uma forma de resgatar o pai, quando foi aconselhado a buscar o auxílio da mãe, que poderia lhe prestar o auxílio necessário. Assim procedendo, o filho foi até a floresta e recebeu dela um cavalo dotado de características mágicas que garantiriam permanentes vitórias ao seu possuidor, como o foi quando Iñigo Guerra logrou resgatar D. Diego.

Esse trecho do Livro de Linhagens narra, portanto, a história de D. Diego Lopes com uma mulher dotada de poderes mágicos e, juntos, foram os progenitores da linhagem de Haro, detentora do senhorio de Biscaia até o século XIV. Da forma como se insere na obra do conde D. Pedro, a lenda apresenta as origens daquela estirpe, construindo a 
imagem de seus antepassados como libertadores do povo biscainho, e atuando como

"uma espécie de prólogo à apresentação da genealogia da família, reforçando o sentido de jogo de parentescos aí evocados: ligações matrimoniais a casas régias e condais externas ou anteriores à dinastia castelhano-leonesa a que estavam sujeitos como vassalos, os senhores de Haro no século XIV.",23

As narrativas sobre a linhagem de Haro simbolizam uma relação com o poder que remete ao valor guerreiro e ao sangue, justificando o domínio sobre Biscaia pelos membros daquela estirpe e dotando-os da "posse de carismas sem os quais esse poder se anularia na sua funcionalidade social" 24 .

Luís Krus aponta ainda uma gênese política para a posição distintiva atribuída pela narrativa aos nobres da linhagem de Haro: a relação com os reis de Castela. As fontes registram a existência efetiva de um Diego Lopes, senhor de Biscaia entre 1170 e 1214, que se rebelou contra Afonso VIII de Castela e Toledo, entre os anos de 1201 e 1205. Considerando que o revolto logrou vantagens sobre o suserano, a narrativa genealógica reafirma

As relações de parentesco atribuídas pelo Livro de Linhagens aos Haros míticos... remete[m] para um tempo em que os reis eram condes a origem do senhorio - e o

${ }^{23}$ KRUS, Luís. Uma variante peninsular do mito de Melusina: a origem dos Haros no Livro de Linhagens do conde de Barcelos, in: A Construção do Passado Medieval: textos inéditos e publicados, Lisboa: IEM - Instituto de Estudos Medievais, 2011, p. 152.

${ }^{24}$ Ibid., p. 162.

Revista Vernáculo n. ${ }^{\circ} 43$ - primeiro semestre/2019

ISSN 2317-4021 
próprio significado da Lenda da Independência de Biscaia, apontam para uma mesma finalidade: a de apresentar o senhorio não sujeito à coroa de Castela ${ }^{25}$.

Dessa forma, a lenda objetivava contribuir para a legitimação da poderosa linhagem de Haro, constituindo o horizonte de harmonia das monarquias com os setores nobiliárquicos e estabelecendo um lugar na ordenação aos segundos, sem com isso reduzir a centralidade dos primeiros. Portanto, a finalidade da narrativa estava voltada para a apresentação de um território não sujeito à autoridade régia castelhana, assim contribuindo para o prestigio sócio-político e os poderes de seus senhores, estratégia literária que foi acompanhada por outras formas de exaltação, a exemplo da alteração do escudo-brasão de Haro - ao qual foram adicionados símbolos referentes às vitórias militares contra os muçulmanos ${ }^{26}$.

Considerando o que ficou exposto, a narrativa registrada pelo Livro de Linhagens possui seu sentido temperado na forja das relações próprios da sociedade feudal ibérica do século XIII, diferentemente de como se pode observar em outras adaptações da mesma lenda da Dama do Pé de Cabra, que possuem como função primeira a do entretenimento, o que não as isenta de serem também imbuídas de um sentido político implícito ou explícito. Comparando as versões do conde

\section{${ }^{25}$ Ibid., p. 164.}

${ }^{26}$ KRUS, Luís. Uma variante peninsular do mito de Melusina: a origem dos Haros no Livro de Linhagens do conde de Barcelos, in: A Construção do Passado Medieval: textos inéditos e publicados, Lisboa: IEM - Instituto de Estudos Medievais, 2011, passim. 
D. Pedro e de Alexandre Herculano, Ana Maria Soares constata a desconstrução e destruição da mundividência original da lenda, em que a

Fada é convertida em bruxa e em criatura ao serviço das forças demoníacas, revelando, desta forma, uma inversão do seu papel fundador assim como o recalcamento e a destruição do feminino, destituído do seu significado ancestral e substituído pelo princípio masculino, associado à misoginia e à visão da mulher como ser inquietante e diabólico ${ }^{27}$.

Ainda segundo a autora, essa modificação teria sido efetivada a partir dos pressupostos do século XIX, "a fim de lançar críticas verdadeiramente mordazes à nobreza e ao clero" ${ }^{28}$. Em se tratando de sua adaptação feita para o veiculo televisivo, a versão da lenda da Dama do Pé de Cabra também carrega elementos do contexto de sua produção. A finalidade de entretenimento que se agrega às narrativas mais contemporâneas não as exime de função política, mas descolam a lenda de seu contexto original, restando na segunda versão mencionada nenhuma referência à política régio-nobiliárquica do século XIII ou a pretensão de compreender aquela narrativa sob a perspectiva historiográfica.

A origem da lenda da Dama do Pé de Cabra, o autor do Livro de Linhagens e suas intenções, a análise historiográfica do conteúdo

${ }^{27}$ SOARES, Ana Maria. A Lenda da Dama do Pé de Cabra: do Livro de Linhagens do Conde D. Pedro de Barecelos a Alexandre Herculano, Limite: Revista de Estudios Portugueses y de la Lusofonía, n. 5, p. 7-30, 2011, p. 28.

${ }^{28}$ Ibid., p. 29.

Revista Vernáculo n. ${ }^{\circ} 43$ - primeiro semestre/2019

ISSN 2317-4021 
lendário, as influências políticas e midiáticas nas versões dos séculos XIX e XX. Nenhuma dessas problemáticas foi levada ao grande público por meio de livros ou de programas de televisão, questão que ficou mais circunscrita ao âmbito acadêmico, marcadamente entre os medievalistas. A restrição no acesso a esse debate não apenas impede a compreensão da narrativa em sua elaboração originária, como, por consequência, deturpa os conhecimentos a respeito da Idade Média, reforçando a interpretação desse período histórico a partir de conotações míticas, de um mundo envolto em magia e trevas.

Como criar formas de dar publicidade a essas reflexões e fazer com que esse exercício de análise historiográfica fique disponível aos potenciais interessados por esse tema? Existe a possibilidade de produzir conteúdo audiovisual que contemple essas demandas? Sim! Ora, basta aproveitar a emergência das tecnologias do século XXI e o advento das novas formas de difusão de informação, cada vez mais individualizadas e disponíveis por meio dos celulares.

\section{O advento do smartphone, novas mídias e a mobilidade da informação}

O celular é atualmente um dos meios de comunicação mais utilizados no dia-a-dia, condição que contrasta com seu emprego inicial, muito mais circunscrito a um público formado por grandes empresários, principalmente no Japão e Estados Unidos, países pioneiros na 
ampliação da tecnologia e utilização desses aparelhos a partir de $1970^{29}$. Se, de início, o uso desse recurso esteve restrito ao recebimento e realização de chamadas, o século XXI trouxe o advento do smartphone, incorporando outras duas tecnologias que revolucionaram as possibilidades de comunicação a partir da segunda metade da centúria anterior: os computadores e a internet.

Em seu surgimento, o computador, instrumento de proporções gigantescas, esteve muito mais voltado para a aplicação nas guerras, distante do acesso aos civis. Essa mesma trajetória marcou igualmente o desenvolvimento da internet que, a princípio pensada para a comunicação militar, passou a ser usada para troca de informações em ambiente acadêmico e posteriormente atingiu a condição de rede aberta ao público, a partir dos anos de 1993-1994, já numa perspectiva da oferta desse serviço visando o lucro ${ }^{30}$.

Atualmente, com a modernização dos computadores e a consequente redução de suas proporções físicas, juntamente com a obsolescência do uso de cabos para a conexão com a internet provocada pelo advento das redes $\mathrm{Wi}-\mathrm{Fi}$ e de dados móveis, os antigos celulares puderam agregar novas tecnologias e possibilitar o advento dos smartphones, responsáveis por colocar essas inovações na palma da mão de seus

${ }^{29}$ SILVA, Sandra Rúbia da. "Eu não vivo sem celular": Sociabilidade, Consumo, Corporalidade e Novas Práticas nas Culturas Urbanas, Intexto, v. 2, n. 17, p. 1-17, 2007, p. 2.

${ }^{30}$ BRIGGS, Asa; BURKE, Peter. Uma história social da mídia: de Gutenberg à Internet, 2. ed. Rio de Janeiro: Zahar, 2006, p. 300.

Revista Vernáculo n. ${ }^{\circ} 43$ - primeiro semestre/2019

ISSN 2317-4021 
usuários, cada vez mais atraídos por uma característica marcante desses aparelhos: a mobilidade.

A adoção dessas tecnologias de caráter móvel, ao que se soma a crescente popularização dos smartphones, fez com que esses aparelhos entrassem no cotidiano da população como ferramenta de uso pessoal, fenômeno que pode ser compreendido pela perspectiva de uma sociedade de consumo, capaz de gerar forte apelo comercial em torno de determinados bens, a exemplo dos novos celulares. Assim sendo, podemos admitir que, hoje, "Os indivíduos utilizam os bens para constituir a si mesmos e ao mundo $[\ldots]^{\prime 31}$, entendimento que torna possível compreender como os telemóveis passaram a constituir parte da identidade de seu portador.

Como analisado por Sandra Rúbia da Silva, esses novos padrões de comportamento geram uma relação de afetividade entre o indivíduo e seu aparelho, perceptível também pelo comportamento de humanização da ferramenta-máquina ${ }^{32}$. Para além disso,

Questões como a estetização da vida cotidiana, a busca pela distinção, o individualismo, o surgimento de novas sociabilidades, a construção de identidades, o fortalecimento de laços sociais e até a mobilização política estão entre os problemas de pesquisa que envolvem uma

${ }^{31}$ SILVA, Sandra Rúbia da. "Eu não vivo sem celular": Sociabilidade, Consumo, Corporalidade e Novas Práticas nas Culturas Urbanas, Intexto, v. 2, n. 17, p. 1-17, 2007, p. 2.

${ }^{32}$ Ibid., p. 10-11.

Revista Vernáculo n. ${ }^{\circ} 43$ - primeiro semestre/2019

ISSN 2317-4021 
leitura cultural do fenômeno da difusão do uso de telefones celulares $^{33}$.

A partir desse conjunto de elementos, é possível perceber a condição central ocupada pelos aparelhos celulares na vida cotidiana da sociedade contemporânea que, ao demandar uma constante conectividade e interatividade, impulsiona os indivíduos à formação de redes de sociabilidade estruturadas em torno de grupos virtuais, ensejando uma lógica de profunda demanda pela instantaneidade, mobilidade e virtualidade das relações contemporâneas. A partir disso, como conclui Sandra Rúbia da Silva, “[...] possuir e usar um celular torna-se uma maneira de estar no mundo [...]"34.

Todos esses elementos, desde o individualismo à formação de grupos de sociabilidade, passando por uma sociedade de consumo que exige a permanente conexão virtual por parte dos sujeitos, promoveram notórias mudanças comportamentais. A presença dos smartphones pode ser facilmente constatada em ambientes públicos, do transporte aos grandes shoppings, provocando alterações nas formas de convívio e de interação entre as pessoas. Chegar à casa de outrem, bares ou restaurantes, e perguntar pela senha do Wi-Fi passou a ser atitude corriqueira dos nossos dias, mas incomum nos primeiros anos do nosso século, assim como o era também receber um vídeo e poder assistir e compartilhar seu conteúdo com um grande número de contatos. Ou seja, o modo de consumir informação também se individualizou e provocou

\footnotetext{
${ }^{33}$ Ibid., p. 4.

${ }^{34}$ Ibid., p. 13.
}

Revista Vernáculo n. ${ }^{\circ} 43$ - primeiro semestre/2019

ISSN $2317-4021$ 
alterações no campo da mídia: seu tipo, direcionamento e formas de consumo foram completamente remodelados pelo advento das plataformas virtuais de disponibilização de informação audiovisual, como o YouTube.

Em 2005, três amigos estadunidenses se depararam com a dificuldade de compartilhar os vídeos produzidos por eles e por outros pessoas ou meios de comunicação ao redor do mundo. Buscando uma solução para esse entrave, Chad Hurley, Steve Chen e Jawed Karim criaram o YouTube. A plataforma experimentou um crescimento vertiginoso quando alguns de seus vídeos atingiram a condição de virais, ou seja, passaram a ser compartilhados e visualizados por milhões de pessoas ao redor do globo ${ }^{35}$. Com tamanho sucesso, a plataforma foi comprada pelo Google logo no ano seguinte.

De acordo levantamento apresentado em reportagem do Portal IG, estima-se que 95\% da população brasileira com acesso a internet visita o YouTube ao menos uma vez ao mês, índice que aumenta em $1 \%$ para a faixa etária de 18 a 35 anos. A pesquisa mostrou ainda que $63 \%$ dos entrevistados não viveriam sem a plataforma de vídeos e, daquele total, $31 \%$ olham para ela como uma fonte de aprendizado. Ainda segundo a matéria, "A pesquisa indica que $79 \%$ dos entrevistados consideram que assistir tutoriais é uma opção melhor do

${ }^{35}$ VENTURA, Felipe. Um breve histórico de como o YouTube ganhou a internet, Gizmodo Brasil, disponível em: <https://gizmodo.uol.com.br/inicio-historiayoutube/>, acesso em: 20 ago. 2018.

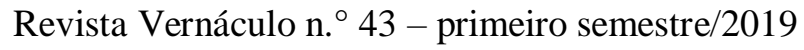

ISSN 2317-4021 
que a leitura de instruções inscritas, indicando uma prevalência significante dos conteúdos em vídeos frente aos de texto" ${ }^{36}$.

Os dados supracitados apontam para uma tendência em considerar o audiovisual como alternativa aos meios escritos, como Arlindo Machado indaga em texto de título provocativo: As Mídias são os Livros do Nosso Tempo? ${ }^{37}$. No entendimento do autor, a sociedade contemporânea costuma associar o livro a uma definição restrita, cristalizada a partir do século $\mathrm{XV}$, que toma o códice cristão como modelo e pressupõe que esse padrão tem como característica determinante a escrita e impressão em papel. Em contraposição a esse entendimento, ele afirma que:

Podemos definir o livro numa acepção mais ampla, como sendo todo e qualquer dispositivo através do qual uma civilização grava, fixa, memoriza para si e para a posteridade o conjunto de seus conhecimentos, de suas descobertas, de seus sistemas de crenças e os vôos de sua imaginação. [...] livro é o instrumento mais poderoso de que pode dispor uma civilização para concentrar o pensamento disperso de seus representantes e conferir-lhe toda a eficácia, difundindo-o rapidamente no tecido social, com um mínimo de custos e de dificuldades ${ }^{38}$.

${ }^{36}$ ECONÔMICO, Brasil. YouTube é acessado por $95 \%$ dos usuários de internet no Brasil, Tecnologia, disponível em: <https://tecnologia.ig.com.br/2017-0728/youtube-usuarios.html>, acesso em: 20 ago. 2018.

37 MACHADO, Arlindo. As mídias são os livros de nosso tempo?, in: CICILIA MARIA KROHLING PERUZZO (Org.), A mídia impressa, o livro e as novas tecnologias, São Paulo: Sociedade Brasileira de Estudos Interdisciplinares, 2002, p. 109-121.

${ }^{38}$ Ibid., p. 110-111.

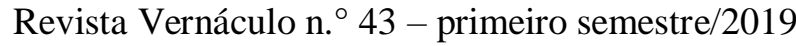

ISSN $2317-4021$ 
Seguindo a reflexão de Arlindo Machado, até o século XV, mesmo o registro escrito era pensado como meio de fixar a memória a fim de ser recitado em público, o que implica em considerar o grande papel que a oralidade desempenhava na transmissão do conhecimento. Assim sendo, o manuscrito era um acessório possibilitador da cultura oral, marcadamente durante a Antiguidade e a Idade Média, quando a troca dos saberes esteve ligada às atividades dos oradores e menestréis, responsáveis por verdadeiros relatos espetacularizados ${ }^{39}$.

Contudo, continua Arlindo Machado, não se pode considerar essa característica oral como exclusiva dos períodos antigo e medieval, haja vista que, ainda no século $\mathrm{XX}$, pensadores que ofereceram relevante contributo para o campo da Ciência pouco escreveram, preferindo expressar suas reflexões por meio da fala, em aulas, debates ou pelos meios de comunicação. Se hoje temos esses conhecimentos em formato escrito, foi devido ao trabalho dos ouvintes que se preocuparam em registrá-los ${ }^{40}$. O autor afirma que, ignorando o poder da oralidade,

Nossas instituições intelectuais, entretanto, ainda parecem se deixar embalar pelas idéias esdrúxulas de que o conhecimento encontra-se associado exclusivamente ao modelo conceitual do texto impresso ou de que só se pode pensar com palavras, com palavras escritas preferencialmente. Persiste ainda largamente nos meios acadêmicos, sobretudo nas áreas de humanidades, uma

${ }^{39}$ Ibid., p. 111.

${ }^{40}$ Ibid., p. 11q-113.

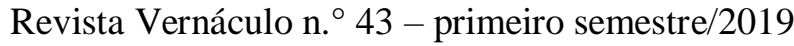

ISSN $2317-4021$ 
tendência generalizada de confundir competência intelectual com talento para a escrita ${ }^{41}$.

Em contraposição ao tradicionalismo acadêmico, as novas gerações têm resistido ao livro impresso e as formas escritas de transmissão do conhecimento, mostrando preferência pelos meios audiovisuais $^{42}$. Diante disso, Arlindo Machado indaga: “[...] por que não recorrer aos novos meios informatizados, como a hipermídia, para transmitir informação e conhecimento a todas essas gerações refratárias aos livros?",43.

Ao longo dos últimos oitenta anos, a sociedade contemporânea assistiu ao crescimento do acesso aos meios de comunicação, principalmente aqueles relacionados aos meios audiovisuais. A pouco e pouco, deixamos de ser uma comunidade de leitores para nos transformarmos em espectadores, condição essa que tem experimentado significativas mudanças a partir de inícios do século XXI, fenômeno também marcado pela passagem da comunicação em massa para outra, mais individualizada e tornada possível pelo advento do streaming ${ }^{44}$.

${ }^{41}$ Ibid., p. 113.

${ }^{42}$ A afirmação a respeito dessa resistência aos meios impressos deve ser, contudo, matizada. Para tanto, faz-se relevante considerar o grande número de analfabetos funcionais no Brasil, o pouco incentivo à leitura oferecido aos jovens brasileiros, o alto custo dos livros, a lentidão da circulação da informação escrita em relação ao conteúdo difundido pelas novas plataformas audiovisuais - acessado de modo imediato, mas restrito pelo acesso à internet -, dentre outros elementos.

${ }^{43}$ Ibid., p. 114.

${ }^{44}$ Forma de transmissão de dados digitais oferecida de maneira contínua por meio de conexão com a internet. Conhecido também como fluxo de mídia, é um dos principais recursos das plataformas de oferta de conteúdo audiovisual em ambiente virtual.

Revista Vernáculo n. ${ }^{\circ} 43$ - primeiro semestre/2019

ISSN 2317-4021 
A assim chamada comunicação em massa é entendida por John B. Thompson como a "[...] produção institucionalizada e difusão generalizada de bens simbólicos através da fixação e transmissão de informação ou conteúdo simbólico" ${ }^{45}$. Nesse sentido, o sociólogo afirma que algumas características desse meio são: seu envolvimento com determinados meios técnicos e institucionais, ou seja, a indústria da mídia; atribuição de valor às formas simbólicas, o que implica em determinar a possibilidade de reprodução da informação de maneira mercadológica; dissociação entre o contexto de produção e de recepção, sendo que os receptores tem pouca capacidade de interferência sobre o que é produzido; extensão da informação veiculada no tempo e no espaço, atingindo locais remotos em momento distinto do que é produzido; e a circulação pública de formas simbólicas. Tomando por base essas premissas, o autor afirma:

[...] a comunicação de massa se diferencia de outras formas de comunicação - como as conversas telefônicas, as teleconferências, ou as produções particulares de vídeo que empregam os mesmos meios técnicos de fixação e transmissão, mas que são dirigidas para um indivíduo ou para um grupo bem restrito de receptores ${ }^{46}$.

Hoje, mais de vinte anos depois de John B. Thompson escrever essas palavras, o cenário dos meios de comunicação sofreu profundas alterações, implicando em não mais aceitar que a mídia possa ser

${ }^{45}$ THOMPSON, John B. A mídia e a modernidade: uma teoria social da mídia, RJ: Vozes, 1998, p. 32.

${ }^{46}$ Ibid., p. 35.

Revista Vernáculo n. ${ }^{\circ} 43$ - primeiro semestre/2019

ISSN 2317-4021 
completamente dissociada das produções particulares de vídeo ou direcionada para um grupo circunscrito de interessados. O fenômeno do YouTube deu destaque a uma variedade de produtores de conteúdo audiovisual, desenvolvidos de maneira individualizada, portanto sem o controle das instituições midiáticas e possíveis de serem produzidos e consumidos de maneira gratuita por meio da plataforma. Graças a isso, constata-se também a extensão da informação a nível global por meio da internet, o que quebra não apenas as barreiras geográficas, mas também temporais.

Tendo o smartphone como ferramenta para a produção de conteúdos, as pessoas têm acesso a diversos recursos, como os aplicativos para edição de vídeos, tornando possível produzir, editar e compartilhar suas criações com os mais variados tipos de público, simplesmente por meio daquilo que o aparelho lhes oferece. Assim sendo, as novas tecnologias quebram o monopólio da mídia tradicional sobre a produção de informação e dão espaço para a emergência de um novo tipo de indivíduo que se entende, para além de outras determinações, como um potencial criador de conteúdo.

Impulsionada por essas novas tecnologias e suas potencialidades, a produção audiovisual de uma análise historiográfica a respeito da lenda da Dama do Pé de Cabra tornou-se viável com o uso do celular, utilizado como meio de desenvolvimento e difusão de conteúdo. No que diz respeito à feitura do material, a pouca experiência com a elaboração de roteiro e os desafios de produzir conteúdo atrativo 
ao público com recursos muito básicos - celulares populares, tripés, microfones simples, programas gratuitos de edição de vídeos, espaços pouco adequados para gravações, dentre outros - foram os maiores entraves experimentados ${ }^{47}$.

Depois de ter sido divulgado no dia 10 de janeiro de 2018, o vídeo A Lenda da Dama do Pé de Cabra: uma análise historiográfica ${ }^{48}$ foi visualizado por um total de 535 pessoas do Brasil, Portugal, Índia, França e Espanha. Os dados estatísticos apresentados pelo YouTube a respeito das visualizações apontam um crescente interesse do público, principalmente a partir de origem externa - impulsionada pela Universidade Federal do Pará (UFPA) e do Facebook - e interna, gerada pela busca na própria plataforma de streaming. Os dados são, contudo, inconclusivos para se observar a localização exata, faixa etária, grau de escolaridade e outras informações mais detalhadas a respeito dos espectadores.

Tendo em vista os debates desenvolvidos nas páginas anteriores, considera-se que a elaboração de um produto audiovisual para a lenda da Dama do Pé de Cabra e sua interpretação historiográfica logrou o

${ }^{47}$ Embora a Universidade Federal do Paraná tenha excelentes técnicos e equipamentos disponíveis para esse tipo de produção, como câmeras semiprofissionais e profissionais, microfones variados, laboratórios de edição de som e vídeo, dentre outros recursos, o curso de extensão teve a intenção de emular um ambiente escolar, marcadamente da rede pública de Ensino Básico, carente desses bens e tecnologias. Essa opção se justifica por ser nesse espaço de ensino que a maior parte dos graduandos terá suas primeiras experiências como professores.

48 Disponível em: https://www.youtube.com/watch?v=LzrrtP4Egvg\&t=14s. Acesso em: 07/01/2019.

Revista Vernáculo n. ${ }^{\circ} 43$ - primeiro semestre/2019

ISSN 2317-4021 
êxito de disponibilizar os conhecimentos a respeito daquela narrativa e do contexto medieval de sua elaboração a um público alargado, capaz de acessar essas informações por meio de um dispositivo presente em seu dia-a-dia e que cabe na palma de sua mão. Esse feito jamais poderia ter sido pensado sem a emergência das novas mídias digitais e as atuais plataformas de compartilhamento de áudio e vídeo, que individualizaram a produção de conteúdos, quebrando a hegemonia das mídias tradicionais, ao mesmo tempo em que tornaram possível o armazenamento e disponibilização de vídeos a quem tem acesso à internet, em todo o globo, em qualquer hora e lugar.

\section{Conclusão}

O desenvolvimento de um audiovisual pautado na análise historiográfica da lenda da Dama do Pé de Cabra a partir do registro do Livro de Linhagens do Conde D. Pedro, distinto daquele produzido pela escrita de Alexandre Herculano e das imagens do Sítio do Picapau Amarelo, buscou preencher a lacuna representada pela inexistência de uma abordagem acadêmica que, alinhada às novas mídias digitais, pudesse lançar um olhar crítico sobre aquela narrativa a partir dos elementos medievais de sua elaboração e dissociar a lenda de um caráter pretensamente lúdico ou unicamente voltado para o entretenimento, como podem sugerir suas versões contemporâneas.

A quantidade de acessos ao vídeo disponível no YouTube, pensado e desenvolvido a partir da fonte histórica e de bibliografia 
especializada, demonstra o interesse de um público específico por essas informações, antes restritas aos livros e artigos de revistas e, portanto, mais acessíveis ao meio acadêmico. Encontravam-se, assim, distantes de um público potencialmente interessado na lenda da Dama do Pé de Cabra, mas que não tem acesso a material escrito especializado ou são resistentes à leitura.

No que toca o mérito da divulgação de conhecimento acadêmico a partir das novas plataformas oferecidas pelas mídias digitais, considera-se que a produção do vídeo A Lenda da Dama do Pé de Cabra: uma análise historiográfica representa uma promissora experiência de desenvolvimento e divulgação de saberes, cujos resultados ainda não podem ser analisados em sua completude e que permanecerão em aberto enquanto esse produto audiovisual estiver disponível ao público.

\section{Referências:}

AURELL, Jaume. Memoria dinástica y mitos fundadores: la construcción social del pasado en la Edad Media. In: La conciencia de los antepasados. Madrid: Marcial Pons, 2014, p. 303-334.

BRIGGS, Asa; BURKE, Peter. Uma história social da mídia: de Gutenberg à Internet. 2. ed. Rio de Janeiro: Zahar, 2006. (Coleção Interface).

ECONÔMICO, Brasil. YouTube é acessado por 95\% dos usuários de internet no Brasil. Tecnologia. Disponível em: <https://tecnologia.ig.com.br/2017-07-28/youtube-usuarios.html>. Acesso em: 20 ago. 2018. 
HERCULANO, Alexandre. A Dama do pé-de-cabra. Domínio Público: Wikisource, 2007.2 Disponível em: <http://www.dominiopublico.gov.br/pesquisa/DetalheObraForm.do?sel ect_action=\&co_obra=81913 >. Acesso em: 20 ago. 2018.

KRUS, Luís. O discurso sobre o passado na legitimação do senhoralismo português dos finais do século XIII. In: A Construção do Passado Medieval: textos inéditos e publicados. Lisboa: IEM - Instituto de Estudos Medievais, 2011, p. 171-179.

KRUS, Luís. Uma variante peninsular do mito de Melusina: a origem dos Haros no Livro de Linhagens do conde de Barcelos. In: A Construção do Passado Medieval: textos inéditos e publicados. Lisboa: IEM - Instituto de Estudos Medievais, 2011, p. 151-170.

Livro de Linhagens do Conde D. Pedro. Edição crítica por José Mattoso. In: Portvgaliae Monvmenta Historica. Nova Série - vol. II. Lisboa: Academia das Ciência, 1980.

MACHADO, Arlindo. As mídias são os livros de nosso tempo? In: CICILIA MARIA KROHLING PERUZZO (Org.). A mídia impressa, o livro e as novas tecnologias. São Paulo: Sociedade Brasileira de Estudos Interdisciplinares, 2002, p. 109-124. (Coleção INTERCOM de comunicação, 15).

MATTOSO, José. Legitimação e linhagem. In: DACOSTA, Arsenio (Ed.). La conciencia de los antepasados. Madrid: Marcial Pons, 2014, p. 17-25.

MOCELIM, Adriana. "Segundo conta a estoria..." A Crônica Geral de Espanha de 1344 como um retrato modelar da sociedade hispânica tardo medieval. Tese (Doutorado em História), UFPR, Curitiba, 2013.

SILVA, Sandra Rúbia da. "Eu não vivo sem celular": Sociabilidade, Consumo, Corporalidade e Novas Práticas nas Culturas Urbanas. Intexto, v. 2, n. 17, p. 1-17, 2007. 
SOARES, Ana Maria. A Lenda da Dama do Pé de Cabra: do Livro de Linhagens do Conde D. Pedro de Barecelos a Alexandre Herculano. Limite: Revista de Estudios Portugueses y de la Lusofonía, n. 5, p. $7-$ 30, 2011.

THOMPSON, John B. A mídia e a modernidade: uma teoria social da mídia. RJ: Vozes, 1998.

VENTURA, Felipe. Um breve histórico de como o YouTube ganhou a internet. Gizmodo Brasil. Disponível em:

<https://gizmodo.uol.com.br/inicio-historia-youtube/>. Acesso em: 20 ago. 2018.

Recebido em 20/08/18 aceito para publicação em 18/01/19 